\title{
EDITORIAL
}

\section{Creativity and its expression forms: sociocultural and media aspects}

Today creativity has become one of the most important key words for the characterizations of a broad and dynamic contemporary sociocultural and media context as an environment where various social and business, culture and arts products are functioning in different ways and forms. These products not necessarily belong to mass marketing of culture or arts - rather they are a result of the rise and prosperity of the trends of non-traditional ways of thinking, creative economy, global cities, non-standard lifestyles and careers. These products essentialy manifest the very heart of the sociocultural and media context of the 21st century. That heart combines not only hardly reconcilable but also contradictory things in a traditional way of thinking; that is why it becomes multifaceted and multicentered as well as multitrended and multidimensional - i.e. essentialy rhizomic one. At this heart the whole everyday life of contemporary human being as of an executor-initiatior, consumer-creator, constitutor-destructor and all the activities and relationships as leisure and work, family and contributors, pleasures and duties, carefreeness and responsibility are developing. Nowadays these fields are not strictly divided into separate parts as it was in the manner of Organizational Age but they are strangely mixed up into the so called melting pot in a postmodern way.

This sociocultural mix of various kinds of activities and interrelations is inseparable from the invasion of mass media and from the growth of its importance under the conditions of almost each our activity. Contemporary mass media are exactly not only the channels of mobility, changeability and communication of these sociocultural products; in some cases media is especially flexibile, and in some other cases media are the social catalysts irresistibly occupying and forcing on all the society and culture their own rules of the game. Under the effect of mass media the new non-traditional forms of creativity are emerging and as a result of these forms the sociocultural formations as the products are broadening the limits of our understanding of culture, arts, society, scales of values, life and career.

This Creativity Studies issue is devoted for the analysis of the fields of the influence of these sociocultural products, choosing some of the main ones, for example, arts, education, sociocultural identity under the conditions of mass culture and media. 